\title{
Pemanfaatan Augmented Reality Sebagai Media Pembelajaran Protozoa
}

\section{Utilization of Augmented Reality as a Learning Media for Protozoa}

\author{
Fatki Sahida $^{1}$, Yusmedi Nurfaizal ${ }^{2}$, Retno Waluyo ${ }^{3}$ \\ ${ }^{1}$ Informatika, Universitas Amikom Purwokerto \\ ${ }^{2}$ Bisnis Digital, Universitas Amikom Purwokerto \\ ${ }^{3,4}$ Sistem Informasi, Universitas Amikom Purwokerto \\ ${ }^{1}$ kushina16hida@gmail.com \\ 2faizal@amikompurwokerto.ac.id \\ ${ }^{2}$ waluyo@amikompurwokerto.ac.id
}

\begin{abstract}
Abstrak
Salah satu upaya meningkatkan mutu pendidikan yaitu dengan pemanfaatan teknologi sebagai media pembelajaran. Media pembelajaran yang digunakan oleh guru SMA XYZ untuk mengajarkan mengenai protozoa pada kelas X MIPA masih menggunakan gambar grafis yang ada dibuku. Permasalahan yang terjadi siswa merasa kesulitan memahami bentuk, nama dan fungsi dari hewan protozoa. Untuk melihat hewan protozoa secara nyata diperlukan alat mikroskpop, namun mikroskop yang dimiliki SMA XYZ belum banyak. Tujuan penelitian ini membuat media pembelajaran dengan teknologi Augmented Reality mengenai Protista pada perangkat mobile. Aplikasi ini hanya akan menampikan empat objek 3D yaitu Paramecium, Flagellata, Sporozoa, dan Amoeba. Metode yang digunakan MDLC yagn terdiri dari enam tahapan yaitu consept, desing, material collecting, assembly, testing, dan Distribution. Hasil penelitian ini berupa aplikasi Augmented Reality sebagai media pembelajaran pembahasan protozoa. Setelah dilakukan pengujian menggunakan alpha test semua tombol/menu berjalan sesuai dengan fungsinya. Kemudian pada pengujian menggunakan beta test, responden menyatakan aplikasi sangat baik untuk digunakan sebagai media pembelajaran.
\end{abstract}

Kata Kunci: Augmented Reality, Media pembelajaran, Protozoa

\begin{abstract}
One of the efforts to improve the quality of education is the use of technology as a medium of learning. The learning media used by XYZ SMA teachers to teach about protozoa in class X MIPA still use graphic images in books. Problems that occur students find it difficult to understand the form, name and function of protozoa animals. To see protozoan animals in real terms, a microscop tool is needed, but there are not many microscopes owned by XYZ SMA. The purpose of this research is to make learning media with Augmented Reality technology about Protists on mobile devices. This application will only display four 3D objects, namely Paramecium, Flagellata, Sporozoa, and Amoeba. The method used by MDLC consists of six stages, namely concept, desing, material collecting, assembly, testing, and distribution. The results of this study are in the form of an Augmented Reality application as a learning medium for the discussion of protozoa. After testing using the alpha test, all buttons / menus run according to their function. Then in testing using the beta test, respondents stated that the application is very good for use as a learning medium.
\end{abstract}

Keywords: Augmented Reality, Learning media, Protozoa,

\section{Pendahuluan}

Salah satu upaya meningkatkan mutu pendidikan yaitu dengan memilih media pembelajaran menjadi sangat penting karena kedudukan media yang strategis untuk keberhasilan pembelajaran [1]. Pendidik menggunakan media pembelajaran untuk membantu menyampaikan pesan kepada peserta didik [2]. Oleh karena itu untuk mencapai keberhasilan dari pembelajaran secara efektif diperlukan media pembelajaran dengan memanfaatkan teknologi [3]. Dengan berkembangnya Teknologi Informasi dan Komunikasi (TIK) saat ini telah mempengaruhi banyak bidang di kehidupan masyarakat tanpa terkecuali bidang kehidupan yang tak luput dari perkembangan teknologi adalah pendidikan [4].

Teknologi pendidikan adalah suatu teknologi yang mendukung kegiatan pendidikan sebagai alat bantu meningkatkan proses belajar siswa dan pengaplikasian teknologi pendidikan membuat kegiatan 
belajar menjadi luas lebih dari sekedar interaksi dengan guru dan murid di dalam ruang dan waktu yang terbatas [5]. Media pembelajaran dikatakan sebagai teknologi pendidikan jika yang dimaksud adalah bentuk fisik dari teknologi atau dengan kata lain merupakan teknologi untuk pembelajaran seperti teknologi cetak, audio, visual, multimedia, komputer, dan teknologi digital lainnnya [6].

Salah satu teknologi pembelajaran adalah Augmented Reality (AR) merupakan media pembelajaran dalam bentuk aplikasi Android, Augmented Reality (AR) merupakan teknologi menggabungkan objek buatan komputer, dua dimensi atau tiga dimensi ke dalam lingkungan nyata di selintas pengguna secara real - time, dan AR merupakan salah satu cara untuk meningkatkan rentang perhatian siswa dan membuat materi pelajaran lebih mudah dipahami, karena dengan Augmented Reality pengguna dapat mengamati model dalam bentuk 3D yang dapat ditampilkan dari berbagai sisi [7]. Selama ini pendidik kelas X MIPA SMA XYZ belum menggunakan Augmented Reality (AR) sebagai media pembelajaran mengenai Protozoa, media yang digunakan untuk mengajarkan Protozoa masih menggunakan gambar grafis yang ada dibuku pembelajaran. Siswa mengalami kesulitan dalam menentukan bentuk, nama dan fungsi dari objek Protozoa. Sehingga hanya 4 siswa yang mendapatkan nilai diatas 67 sebagai nilai Kriteria Ketuntasan Minimal (KKM) pada pembelajaran Protozoa seperti pada Gambar 1.

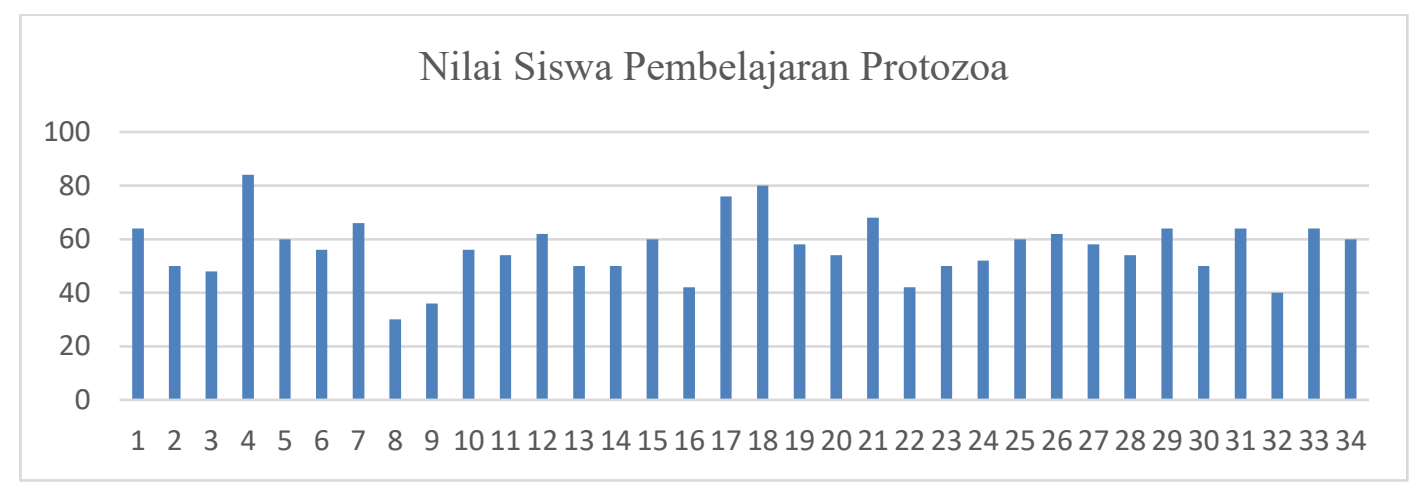

Gambar 1. Nilai Siswa Pada Pembelajaran Protozoa

Pada [8] Augmented Reality merupakan kombinasi dunia maya (virtual) dan dunia nyata (real) sehingga pengguna dapat merasakan objek virtual berada di lingkungannya, dan memberikan pengalaman visualisasi yang nyata. Keuntungan penggunaan Augmented Reality (AR) untuk media pembelajaran yaitu mempermudah pemahaman pengguna terhadap objek yang dipelajari serta lebih efektif dari buku sebagai media pembelajaran [9]. Augmented Reality memiliki kelebihan diantaranya lebih interaktif dan efektif, mudah dioperasikan, dapat menggunakan berbagai media dan biaya yang dibutuhkan tidak terlalu banyak karena hanya menampilkan beberapa obyek. sedangkan kelemahannya antara lain memerlukan kapasitas memori yang besar, belum banyak orang yang punya kemampuan membuat Augmented Reality dan sensitif terhadap perubahan sudut pandang [10].

Penelitian yang dilakukan oleh [11] membuat aplikasi Augmented Reality Markerless yang digunakan sebagai media pembelajaran siswa SMK YPT 2 Purbalingga untuk memvisualisasikan mesin roda dua berupa 3D model. Selain itu penelitian [12] untuk meningkatkan minat baca mengenai budaya rumah adat Tongkonan, maka dibuat media pembembelajaran menggunakan Augmented Reality. Dengan menerapkan Augmented Reality sebagai media pembelajaran membantu meningkatkan minat baca mempelajari budaya rumah adat sehingga mengatasi permasalahan yang ada. Sedangkan [13] media pembelajaran beruapa aplikasi AR untuk pengenalan buah-buahan membuat siswa menjadi lebih antusias dalam belajar sehingga dengan aplikasi ini membantu merangsang pola pikir siswa serta siswa lebih berpikir kritis. Dengan menerapakan Augmented Reality dapat merasakan visualisasi yang nyata sehingga bisa digunakan menjadi media pembelajaran.

Dari latar belakang yang telah diuraikan maka tujuan penelitian ini membuat aplikasi Augmented Reality (AR) sebagai media pembelajaran Protozoa melalui perangkat Mobile dengan menggunakan metode pengembangan multimedia MDLC (Multimedia Development Life Cycle) untuk membantu siswasiswi memahami materi Protozoa yang didalamnya terdapat pembelajaran untuk pengamatan dari jenisjenis Protozoa diantaranya Flagellata, Paramecium, Sporozoa dan Amoeba agar siswa mudah memahami bentuk dari masing-masing jenis Protozoa dan menentukan baik nama maupun fungsi dari stiap jenis Protozoa yang di tampilkan di Augmented Reality dengan objek 3D (3 Dimensi). 


\section{Metode Penelitian}

Metode MDLC digunakan dalam pengembangan media pembelajaran yang menghasilkan media pembelajaran multimedia interaktif sehingga mempermudah penyampaian pesan kepada peserta didik [14]. Pada metode MDLC untuk pengembangan multimedia memiliki enam tahapan yaitu consept, desing, material collecting, assembly, testing, dan Distribution, berikut tahapan-tahapan pengembangan multimedia [15]:

Tahap pertama yaitu consept (konsep) merupakan tahap menentukan tujuan pengguna program. Selain itu menentukan macam aplikasi dan tujuan aplikasi Pada tahap ini menentukan konsep media pembelajaran yang akan dibuat menggunakan Augmented Reality membahas mengenai protozoa pada mapel biologi kelas X MIPA. Pada tahapan ke dua membuat design atau perancangan spesifikasi arsitektur program, gaya, tampilan, dan kebutuhan material atau bahan untuk program [15]. Rancangan bentuk tampilan aplikasi, bentuk objek Protozoa, dan kebutuhan material atau bahan untuk media pembelajaran materi Protozoa.

Tahap ke tiga merupakan tahapan pengumpulan bahan yang sesuai dengan kebutuhan. Tahap ini juga dapat dikerjakan pararel maupun linear dengan tahapan Assembly [15]. Pengumpulan bahan materi untuk membuat media pembelajaran AR antara lain materi pembelajaran Protozoa, Gambar, objek 3D, dan audio. Sedangkan tahap ke empat merupakan pembuatan dari aplikasi, dimana setelah mendapatkan bahan yang dibutuhkan [15]. Pada tahapan ini peneliti menggunakan software dan hardware, seperti Unity, blender, webcame, komputer, dan hanphone. Hal pertama yang dilakukan adalah membuat objek tiga dimensi dari Protozoa, dan selanjutnya pembuatan desain icon, Marker, dan User Interface dari aplikasi. Setelah semua bahan untuk software Unity sudah terpenuhi maka mulai menyusun tata letak desain, ukuran, dan tampilan di kamera Augmented Reality.

Tahap ke lima merupakan Testing, Dalam tahapan ini untuk melakukan pengujian aplikasi dengan menguji fungsi dari aplikasi media pembelajaran. Pengujian alpha test digunakan untuk menguji fungsional pada setiap menu/tombol yang ada pada aplikasi. Sedangkan beta test untuk mengetahui kualitas aplikasi sudah sesuai harapan dari para pengguna. Pengujian dilakukan dengan mengumpulkan data berupa kuesioner dari siswa kelas X MIPA sebagai responden. Untuk menentukan jumlah responden menggunakan persamaan slovin dengan tingkat kesalahan 10\%. Persamaan Slovin [16] :

$$
\begin{aligned}
& \mathrm{n}=\frac{N}{\left(1+N e^{2}\right)} \\
& \text { Keterangan: } \\
& \mathrm{n} \quad=\text { Jumlah Sampel } \\
& \mathrm{N}=\text { Total Populasi } \\
& \mathrm{e} \quad=\text { Tingkat kesalahan dalam pengambilan sambel }(10 \%)
\end{aligned}
$$

Dengan jumlah polulasi sebanyak 102 siswa maka setelah dilakukan perhitungan mengunakan persamaan slovin diperlukan sejumlah 50 responden. Rumus perhitungan skala Likert [8] dari hasil kuesioner sebagai berikut :

\section{Total Skor $\quad=($ Total Pemilih $\mathrm{x}$ Skor $)$}

Skor Tertinggi $\quad=$ (Nilai Tertinggi $\mathrm{x}$ Jumlah Pertanyaan $\mathrm{x}$ Jumlah Responden $)$

Rumus Index \% = (Total Skor)/(Skor Tertinggi) X 100

Setelah dilakukan perhitungan dengan skala likert, Kemudian untuk mengetahui kualitas aplikasi sesuai harapan pengguna maka menggunakan ratting scale sebagai berikut:

\begin{tabular}{ll}
\multicolumn{2}{c}{ Tabel 1. Ratting Scale [8] } \\
\hline Nilai & Kriteria \\
\hline $81 \%-100 \%$ & Sangat Baik \\
$61 \%-80 \%$ & Baik \\
$41 \%-60 \%$ & Cukup \\
$21 \%-40 \%$ & Tidak Baik \\
$0 \%-20 \%$ & Sangat Tidak Baik \\
\hline
\end{tabular}

Tahap ke enam yaitu Distribution, setelah dilakukan pengujian dan pengguna merasa sudah baik maka aplikasi Augmented Reality ini disimpan yang kemudian di distribusikan kepada seluruh siswa kelas X MIPA sebagai pengguna.

\section{Hasil dan Pembahasan}

Konsep media pembelajaran yang akan dibuat berupa aplikasi yang menampilkan objek tiga dimensi dari Protozoa dan pada objek ini juga terdapat keterangan tentang objek dan keterangan dari setiap bagian 
objek. Aplikasi juga mendukung adanya fitur screenshot, menu kuis untuk membuat siswa - siswi mengingat kembali apa yang sudah dipelajari dalam aplikasi, seperti fungsi dari objek, perbedaan bentuk dari objek satu dengan yang lain, dan siswa-siswi dapat berhasil menentukan nama dari objek yang ditampilkan.

Selanjutnya tahap design yang dibuat untuk mempermudah dalam proses pembuatan ataupun pengoperasian dari aplikasi. Design Layout pada gambar 2. merupakan menu utama aplikasi yang dibuat terdiri dari start, kuis, dan keluar. Menu start berfungsi sebagai menu untuk memindai atau scan Marker. Menu kuis untuk memulai kuis. Sedangkan menu keluar untuk keluar dari aplikasi. Design layout pada gambar 3 merupakan menu start terdapat tombol screenshot, flash, gallery, kuis, dan X (silang). Dapat dilihat juga ada tampilan objek tiga dimensi jika memulai scan pada Marker. Untuk tombol kue di sini memiliki fungsi yang sama dengan fungsi menu utama. Tombol screenshot berfungsi untuk screenshot tampilan objek. Fungsi dari gallery adalah menyimpan dari foto hasil screenshot. Tombol flash berfungsi untuk menyalakan flash pada lampu, dan terakhir tombol X (silang) untuk keluar dari aplikasi.

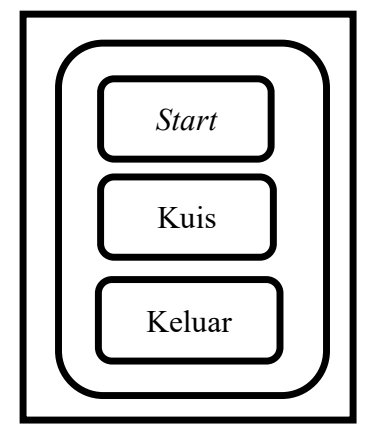

Gambar 2. Design Layout Menu Utama

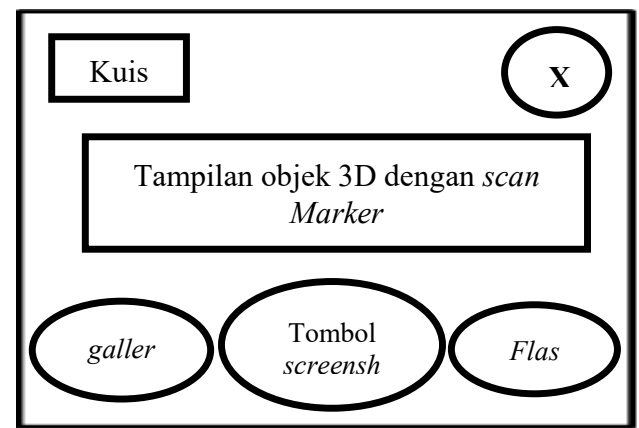

Gambar 3. Design Layout Menu Start

Pada tahapan Material Collecting dilakukan pengumpulan bahan materi untuk membuat media pembelajaran AR materi Protozoa menyerupain hewan atau Protozoa. Materi yang dikumpulkan untuk aplikasi ini adalah gambar, objek 3D, dan audio.

Tabel 2. Material Collecting

\begin{tabular}{|c|l|c|c|l|}
\hline No. & \multicolumn{1}{|c|}{ Nama File } & Ukuran & Jenis File & \multicolumn{1}{|c|}{ Keterangan } \\
\hline 1. & Gambar : & & & Dibuat menggunakan \\
& 1) Background Menu & $300 \mathrm{~Kb}$ & & CorelDraw 2017 \\
& 2) Pop Up Menu & $120 \mathrm{~Kb}$ & & \\
& 3) Icon App & $45 \mathrm{~Kb}$ & .png & \\
& 4) Button Pack & $100 \mathrm{~Kb}$ & & \\
\hline 2. & 5) Icon Pack & $100 \mathrm{~Kb}$ & & \\
& Object 3D : & & & Dibuat menggunakan \\
& 1) Amoeba 2) Flagellata & $1,5 \mathrm{Mb}$ & & Blender 2.81 \\
& 3) Paramecium & $500 \mathrm{~Kb}$ & .blend & \\
& 4) Sporozoa & $1,2 \mathrm{~Kb}$ & & \\
\hline 3 & Audio: & & & Diunduh dari Internet \\
& 1) Button Click & $30 \mathrm{~Kb}$ & & (free royalty soud) \\
& 2) Pop Up Sound & $40 \mathrm{~Kb}$ & .wav & \\
& 3) Camera Shutter & $35 \mathrm{~Kb}$ & & \\
\hline
\end{tabular}

Tahapan Assembly merupakan tahap pembuatan objek multimedia berdasarkan perancangan yang telah dibuat. Hal pertama yang dilakukan adalah membuat objek tiga dimensi (3D) dari Protozoa, dan selanjutnya pembuatan desain icon, Marker, dan User Interface dari aplikasi. Kemudian menyusun tata letak desain, ukuran, dan tampilan di kamera Augmented Reality. Pembuatan objek tiga dimensi yang nantinya akan muncul saat kamera sudah memindai atau scan pada Marker. Objek tiga dimensi ini dibuat dengan menggunakan software Blender 3D, dan hanya membuat objek tiga dimensi (3D) Flagellata, Paramecium, Sporozoa dan Amoeba 


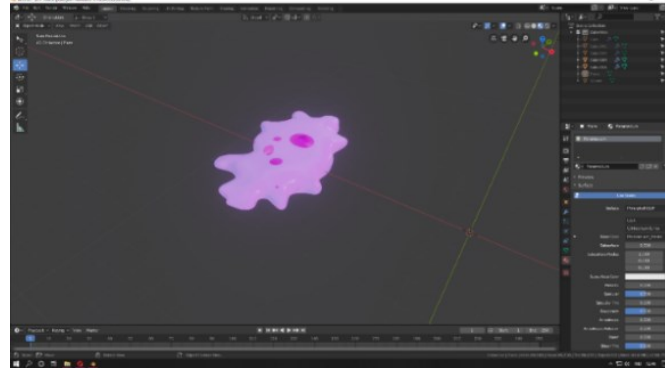

Gambar 4. Objek 3D Amoeba

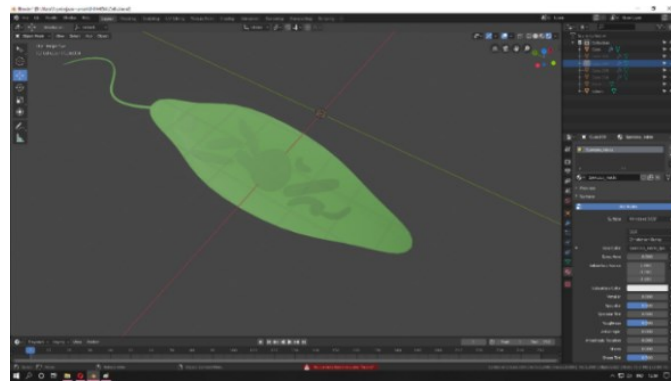

Gambar 6. Objek 3D Flagellata

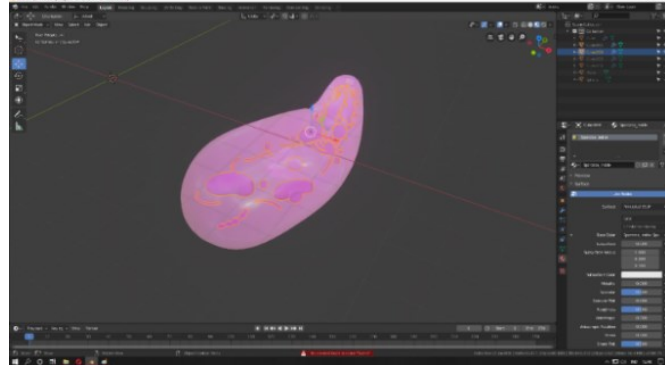

Gambar 5. Objek 3D Sporozoa

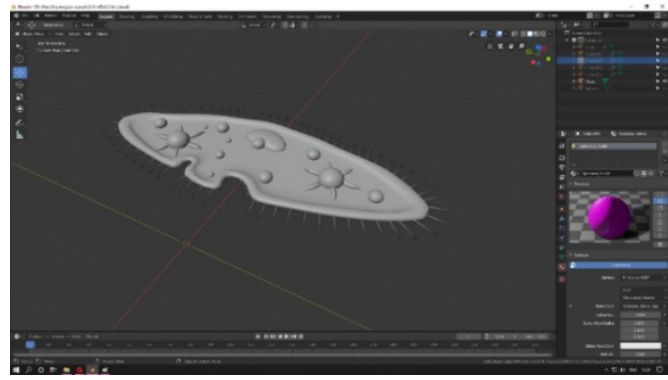

Gambar 7. Objek 3D Paramecium

Pembuatan User Interface Pada menu utama terdiri dari tiga menu yaitu start, kuis, dan keluar sedangkan Pada menu start terdapat empat menu yaitu menu kuis, keluar, gallery, screenshoot, dan flash.

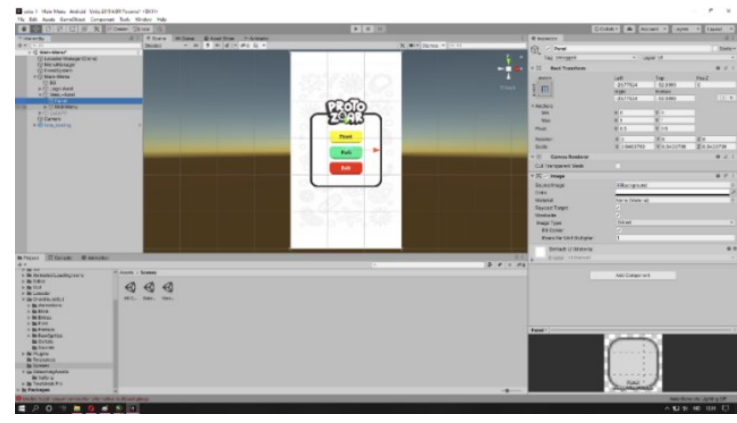

Gambar 8. Tampilan Menu Utama

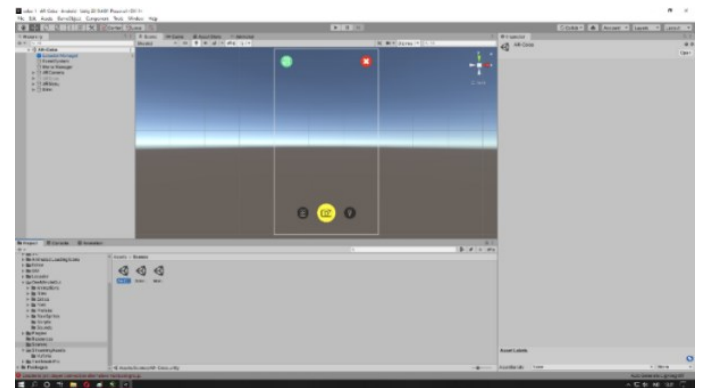

Gambar 9. Tampilan Menu Start

Hasil aplikasi pada menu utama yang terdiri dari tiga menu, yaitu start, kuis dan keluar. sedangkan pada menu start terdapat empat menu yaitu menu kuis, keluar, gallery, screenshoot, dan flash.

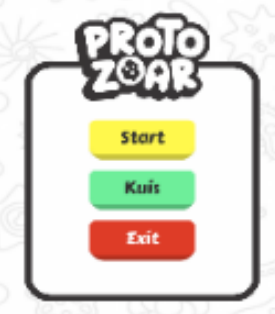

Gambar 10. Hasil Aplikasi Menu Utama

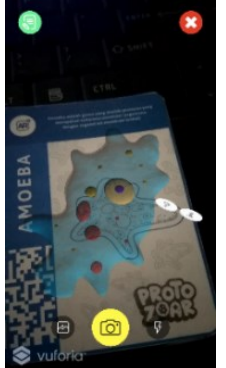

Gambar 11. Hasil Aplikasi Menu Start

Aplikasi sudah dapat menampilkan aplikasi dengan scan marker objek. Setelah klik i makan akan muncul i di setiap bagian objek, klik i pada bagian objek maka kan muncul nama dari bagian terdebut. ada tampilan kuis ini terdapat waktu untuk membuat setiap soal memiliki batasan waktu untuk menjawab soal. tampilan kuis juga memiliki tombol menu untuk kembali ke menu awal, tombol skip untuk melakukan mengganti soal selanjutnya jika dirasa sulit, dan ada skor untuk setiap soal maupun menampilkan jumlah skor yang didapat. 


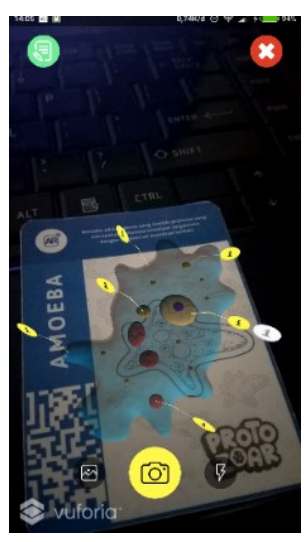

Gambar 12. Hasil Setelah klik i

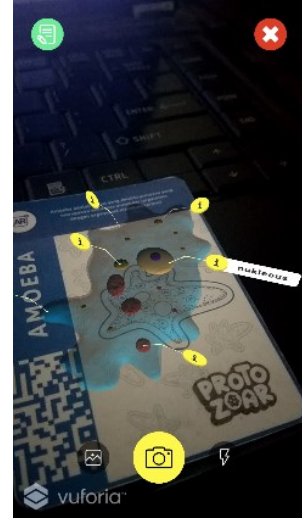

Gambar 13. Hasil Nama Bagian Objek

Kemudian pada tahapan testing ini dilakukan dengan alpha testing dan beta testing. Pengujian menggunakan alpha test untuk menguji fungsional pada setiap menu/tombol yang ada pada aplikasi. Pengujian yang dilakukan adalah untuk menguji fungsi dari aplikasi media pembelajaran [5]. Berikut Table hasil pengujian :

Tabel 3. Pengujian Aplikasi augmnted Realty

\begin{tabular}{lll}
\hline Pengujian & Detail Pengujian & Hasil \\
& & \\
\hline Halaman Awal & Ketuk Untuk Memulai & Berhasil \\
Menu Utama & Tombol Start & Berhasil \\
& Tombol Kuis & Berhasil \\
& Tombol Keluar & Berhasil \\
Menu Start & Tombol Screenshot & Berhasil \\
& Tombol Gallery & Berhasil \\
& Tombol flash & Berhasil \\
& Tombol Kuis & Berhasil \\
& Tombol Keluar & Berhasil \\
& Scan & Berhasil \\
& Tombol arah $<$ & Berhasil \\
Menu Gallery & Tombol arah $>$ & Berhasil \\
& Menu Gallery & Berhasil \\
& Tombol Share & Berhasil \\
& Waktu & Berhasil \\
Menu Kuis & Skor & Berhasil \\
& Jumlah Skor & Berhasil \\
& Tombol Menu & Berhasil \\
& Tombol Skip & Berhasil \\
\hline
\end{tabular}

Dari hasil pengujian pada aplikasi yang tertera pada tabel di atas, dapat disimpulkan bahwa aplikasi ini sudah berjalan sesuai keinginan yang diharapkan, atau tidak ada kesalahan pada fungsional aplikasi AR.

Pengujian dengan beta test menggunakan data hasil kuesioner yang telah dibagikan kepada responden dengan 5 butir pertanyaan, Hasil kuesioner responden terdapat pada tabel 4.

Tabel 4. Hasil Kuesioner

\begin{tabular}{cccccc}
\hline Pertanyaan & \multicolumn{5}{c}{ Jawaban Responden } \\
\cline { 2 - 6 } Ke & $S S$ & $S$ & $N$ & $T S$ & $S T S$ \\
\hline 1 & 24 & 25 & 1 & & \\
2 & 18 & 58 & 1 & & 2 \\
3 & 16 & 32 & 1 & 1 & 2 \\
4 & 19 & 23 & 6 & & \\
5 & 28 & 19 & 2 & 1 & 4 \\
\hline Jumlah & 105 & 157 & 11 & 2 & \\
\hline
\end{tabular}


Keterangan Penilian:

Sangat Setuju (SS) $\quad=5$

Setuju (S) $\quad=4$

Netral $(\mathrm{N}) \quad=3$

Tidak Setuju (TS) $\quad=2$

Sangat Tidak Setuju (STS) $=1$

Rumus perhitungan skala Likert [8] dari hasil kuesioner dapat menghasilkan sebagai berikut :

Total Skor $\quad=($ Total Pemilih $\mathrm{x}$ Skor $)$

$=(105 \times 5)+(157 \times 4)+(11 \times 3)+(2 \times 2)+(4 \times 1)$

$=525+628+33+4+4$

$=1194$

Skor Tertinggi $=($ Nilai Tertinggi $\mathrm{x}$ Jumlah Pertanyaan $\mathrm{x}$ Jumlah Responden)

$=(5 \times 5 \times 50)$

$=1250$

Rumus Index $\%=\frac{\text { Total Skor }}{\text { Skor Tertinggi }} X 100$

$$
\begin{aligned}
& =\frac{1194}{1250} X 100 \\
& =95.52 \%
\end{aligned}
$$

Dari hasil perhitungan kuesioner didapatkan nilai index sebesar 95,52\%. Berdasarkan rating scale pada tabel 1. Maka aplikasi ini masuk dalam kriteria sangat baik. Sehingga dari hasil berikut dapat diambil kesimpulan bahwa aplikasi Augmented Reality sebagai media pembelajaran protozoa sudah dapat membantu siswa SMA XYZ dalam menentukan bentuk, nama, dan fungsi dari objek Protozoa.

Pada tahapan Distribution ini merupakan aplikasi yang sudah dilakukan pengujian dengan kriteria sangat baik disimpan dalam suatu media penyimpanan, dan diberikan kepada pengguna. Pada tahapan ini aplikasi Augmented Reality media pembelajaran akan dilakukan pendistribusian, yang dimana aplikasi ini berbentuk file .apk.

\section{Kesimpulan}

Pada penelitian ini telah dibuat aplikasi Augmented Reality sebagai media pembelajaran untuk kelas X MIPA pada mata pelajaran biologi dengan pembahasan protozoa menggunakan perangkat mobile berbasis Android yang memiliki informasi jenis-jenis Protozoa beserta nama bagian dan fungsi pada setiap bagian dari Sporozoa, Amoeba, Flagellata, dan Paramecium. Setelah diuji dengan alpha test semua tombol/menu dapat berfungsi dengan baik tanpa ada kesalahan. Sedangkan pengujian menggunakan beta test menggunakan kuesioner diperoleh nilai indexs sebesar 95,52\%, sehingga disimpulkan bahwa aplikasi masuk dalam dikriteria sangat baik. dengan demikian aplikasi ini dapat digunakan sebagai media pembelajaran pada pembahasan protozoa bagi kelas X MIPA SMA XYZ. Saran untuk pengembangan dari penelitian selanjutnya agar penelitian ini kedepannya bisa lebih baik, yaitu aplikasi Augmented Reality diperlukan penambahan animasi dan dapat digunakan di platform lain seperti IOS, website dan lain-lain.

\section{Daftar Pustaka}

[1] U. A.T.A Duludu, Buku Ajar Kurikulum Bahan dan Media Pembelajaran PLS. Yogyakarta: DEPPUBLISH, 2017.

[2] I. Mustaqim, "PEMANFAATAN AUGMENTED REALITY SEBAGAI MEDIA PEMBELAJARAN,” J. Pendidik. Teknol. dan Kejuru., vol. 13, no. 2, pp. 174-183, 2016.

[3] I. Darimi, "TEKNOLOGI INFORMASI DAN KOMUNIKASI SEBAGAI MEDIA PEMBELAJARAN PENDIDIKAN AGAMA ISLAM EFEKTIF,” J. Pendidik. Teknol. Inf., vol. 1, no. 2, pp. 111-121, 2017, doi: 10.1007/s11068-008-9037-4.

[4] A. Ismayani, Cara Mudah Membuat Aplikasi Pembelajaran Berbasis Android dengan Thunkable. Jakarta: Elex Media Komputindo, 2018.

[5] E. Switri, Teknologi Dan Media Pendidikan Dalam Pembelajaran. Pasuruan: Qiara Media, 2019.

[6] M. Yaumi, Media dan Teknologi Pembelajaran. Jakarta: PRENADAMEDIA GROUP, 2018.

[7] A. Ismayani, Membuat Sendiri Aplikasi Augmented Reality. Jakarta: PT Alex Media Komputindo, 2020.

[8] S. Asmiatun, N. Wakhidah, and A. N. Putri, Penerapan Teknologi Augmented Reality Dan GPS 
Tracking Untuk Deteksi Jalan Rusak. Yogyakarta: DEPPUBLISH, 2020.

[9] E. Setiawan, U. Syaripudin, and Y. A. Gerhana, "Implementasi Teknologi Augmented Reality pada Buku Panduan Wudhu Berbasis Mobile Android," J. Online Inform., vol. 1, no. 1, p. 28, 2016, doi: 10.15575/join.v1i1.8.

[10] I. Mustaqim and N. Kurniawan, "PENGEMBANGAN MEDIA PEMBELAJARAN BERBASIS AUGMENTED REALITY,” J. Edukasi Elektro, vol. 1, no. 1, pp. 36-48, 2017.

[11] H. Hermawan, R. Waluyo, and M. Ichsan, "Pengembangan Media Pembelajaran Mesin Menggunakan Teknologi Augmented Reality," J. Innov. Inf. Technol. Appl., vol. 1, no. 01, pp. 17, 2019, doi: 10.35970/jinita.v1i01.88.

[12] V. A. Johan and A. C. Syarif, "Penerapan Augmented Reality Sebagai Media Pembelajaran Budaya Rumah Adat Sulawesi Selatan," J. Temat., vol. 3, no. 1, pp. 15-22, 2015.

[13] A. Pramono and M. D. Setiawan, "Pemanfaatan Augmented Reality Sebagai Media Pembelajaran Pengenalan Buah-Buahan," J. INTENSIF, vol. 3, no. 1, p. 54, 2019, doi: 10.29407/intensif.v3i1.12573.

[14] M. Mustika, E. P. A. Sugara, and M. Pratiwi, "Pengembangan Media Pembelajaran Interaktif dengan Menggunakan Metode Multimedia Development Life Cycle,” J. Online Inform., vol. 2, no. 2, pp. 121-126, 2017, doi: 10.15575/join.v2i2.139.

[15] Sugiyono, Metode Penelitian Kuantitafif, Kualitatif, dan R\&D. Bandung: Alfabeta, 2019.

[16] Sugiyono, Metode Penelitian Kuantitatid Kualitatif dan R\&D. Bandung: Alfabeta, 2011. 